\title{
DOES BLOOD GROUP IDENTIFY LIP PRINTS?
}

\author{
AMBRISH KAUSHAL ${ }^{1} \&$ PRIYANKA CHHABRA ${ }^{2}$ \\ ${ }^{1}$ Research Scholar, Department of Forensic Science, SBAS, Galgotias University, Greater Noida \\ ${ }^{2}$ Assistant Professor, Department of Forensic Science, SBAS, Galgotias University, Greater Noida
}

\begin{abstract}
Introduction: The lip prints are the lines and fissures which are present in the transition zone of the human lips between the mucosa and skin. They are considered permanent and unchangeable after the death of the individual and are unique except in the cases of monozygotic twins. It is acceptable as the evidence that can be left at the crime scene by the culprit and this evidence helps in the identification of an individual. The blood group of the person is considered as another unchangeable biological record which can be obtained from crime scene to get help in identifying an individual.

Aims and objectives: In this study, it has been tried to perform a correlation between the blood groups and lip prints which can serve as an aid in forensic identification.

Methodology: For this study, the lip prints were taken from 100 individuals by traditional lipstick paper method and $1 \mathrm{ml}$ of blood is withdrawn for determining the $A B O$ blood groups for correlating lip print pattern with blood groups as per the classification system of Suzuki and Tsuchihashi.

Result: There was no correlation found between the lip prints and blood groups.

Conclusion: However, no correlation exists between the two samples but they are useful in forensic identification due to their unique character.
\end{abstract}

KEYWORDS: ABO Blood groups, lip prints, forensic identification, gender identification, forensic odontology.

Received: May 29, 2021; Accepted: Jun 19, 2021; Published: Jul 06, 2021; Paper Id.: IJDRDDEC20211

\section{INTRODUCTION}

Forensic science is the application of scientific methods and techniques to matter under investigation by a court of law and personal identification is an integral part of forensic investigation. The methods of personal identification comprise several techniques but lip prints obtained from crime scene and from the suspect may be useful in identification with narrowing the investigation process. The other part of biological record which remains unchanged throughout life is the blood group. Identifying the blood group of a person obtained from crime scene help as an aid in personal identification. Blood spatter refers to the pattern of bloodstain is an important clue in identifying the weapon used to inflict the injury and it also helps to determine whether the victim was moving or motionless when injured. These are the most important biological traces which are often found at the crime scene and proper knowledge can interpret results and makes it possible to get closer to the truth, solve that particular crime and bring the perpetrator to justice. In India, several racial and ethnic groups show different lip print patterns along with blood groups. Hence, the present study has been performed to find out if there is any relation between lip prints and blood group in North Indian population ${ }^{1,2}$. 


\section{MATERIAL AND METHODS}

The present study has been performed in Department of Forensic science, Galgotias University, Greater Noida, Uttar Pradesh. A total number of 100 (63 females, 37 males) individuals have been involved in the study between the age group of 19-27 years. The study population belongs to the region of Lucknow and Greater Noida. All the individuals have been properly investigated regarding any episodes of trauma or surgery performed in the facial region or lip region with their vitals under normal range. An informed consent has been obtained by each and every individual regarding the procedure of making lip impressions and blood group investigation. The lip prints were obtained by traditional lipstick method by applying a thin layer of lipstick on upper and lower lip and asking the individuals to gently press the lips on the white rectangular paper to get the lip prints. The lip prints were analyzed using Suzuki and Tsuchihashi criteria. The blood group has been identified by withdrawing the blood and checking the blood group with combined ABD monoclonal antibody kit for blood typing (J. Mitra Company Private Limited ${ }^{\mathrm{TM}}$ ) with all the precautions. The individuals have been informed regarding their blood group type obtained after the test results.

\section{RESULTS}

This study comprised of 100 individuals out of which there were 63 females and 37 males. In females the predominant lip pattern found was Type I followed by Type II, III, and Type I' according to Suzuki and Tsuchihashi criteria whereas in males the predominant lip pattern was found to be Type I' along with by Type II, I and Type III. In the case of blood group out of 63 females, 26 females have $\mathrm{B}^{+}$blood group while remaining out of 37 females, 20 have the blood group of $\mathrm{A}^{+}, 10$ have the blood group of $\mathrm{AB}^{+}$and 7 have the blood group of $\mathrm{O}^{+}$. In males out of $37 ; 22$ have $\mathrm{B}^{+}$blood group, 8 have $\mathrm{A}^{+}, 5$ have $\mathrm{O}^{+}$and 2 have $\mathrm{AB}^{+}$blood group (Table 1).

In the case of 26 females having $\mathrm{B}^{+}$blood group the lip pattern was of Type I (14 females) and I' (12 females). Twenty females having $\mathrm{A}^{+}$blood group showed lip print pattern of Type I' (13 females) and Type II ( 07 females) while 10 females with $\mathrm{AB}^{+}$blood group showed the lip print pattern of Type I ( 06 females), III ( 03 females) and Type II ( 01 female) and 7 females with $\mathrm{O}^{+}$blood group showed the lip pattern of Type II ( 04 females) and Type III ( 03 females) (Table 2).

In the case of 22 males having $\mathrm{B}^{+}$blood group, they showed the lip print pattern of Type I' (14 males) and Type II (08 males). Eight individuals with blood group $\mathrm{A}^{+}$showed lip pattern of Type I (06 males) and Type III (02 males), while 5 males with $\mathrm{O}^{+}$showed the lip pattern of Type II (04 males) and Type I (01 male) and 2 males with $\mathrm{AB}^{+}$blood group showed the lip print pattern of Type III respectively (Table 3).

Table 1: Blood Group in Males and Females

\begin{tabular}{|l|c|c|c|c|}
\hline \multicolumn{5}{|c|}{ Blood Group } \\
\hline \multirow{4}{*}{$\begin{array}{l}\text { Females } \\
\text { Males }\end{array}$} & $\mathbf{A}^{+}$ & $\mathbf{B}^{+}$ & $\mathbf{A B}^{+}$ & $\mathbf{O}^{+}$ \\
\cline { 2 - 5 } & 20 & 26 & 10 & 07 \\
\cline { 2 - 5 } & 08 & 22 & 02 & 05 \\
\hline
\end{tabular}

Table 2: Lip Prints found in ABO Blood Groups in Females

\begin{tabular}{|l|c|c|c|c|}
\hline \multicolumn{5}{|c|}{ Blood Group (Females) } \\
\hline \multirow{3}{*}{ Lip Print Types } & $\mathbf{A}^{+}$ & $\mathbf{B}^{+}$ & $\mathbf{A B}^{+}$ & $\mathbf{O}^{+}$ \\
\cline { 2 - 5 } Type I & - & $14 / 26$ & $06 / 10$ & - \\
\hline Type I' & $13 / 20$ & $12 / 26$ & - & - \\
\hline Type II & $07 / 20$ & - & $01 / 10$ & $04 / 07$ \\
\hline Type III & - & - & $03 / 10$ & $03 / 07$ \\
\hline
\end{tabular}


Table 3: Lip Prints Found in ABO Blood Groups in Males

\begin{tabular}{|l|r|r|r|r|}
\hline \multirow{2}{*}{ Lip Print Types } & $\mathbf{A}^{+}$ & $\mathbf{B}^{+}$ & $\mathbf{A B}^{+}$ & $\mathbf{O}^{+}$ \\
\cline { 2 - 5 } & \multicolumn{4}{|c|}{} \\
\hline Type I & $06 / 08$ & & & $01 / 05$ \\
\hline Type I' & & $14 / 22$ & & \\
\hline Type II & & $08 / 22$ & & $04 / 05$ \\
\hline Type III & $02 / 08$ & & $02 / 02$ & \\
\hline
\end{tabular}

\section{DISCUSSION}

This study has been performed to find out the correlation between lip print patterns and blood groups. It was seen that in the overall study the predominant lip pattern was Type I and I' which was consistent with the earlier studies done by Prerna Gupta $^{1}$, Vahanwalla and Parekh ${ }^{2}$, and Prateek Rastogi ${ }^{3}$ who also found Type I lip pattern to be predominant in their subjects according to the geographical region the study performed. The consideration of males and females separately in the present study it was found that in both the sexes the predominant pattern was Type I and I' along with Type II and III which was somewhat different from the study of Vahanwalla ${ }^{4}$ who found Type II and III in females and Type I, I' and Type IV in males which is due to a reason that lip prints are unique identification marks and are different with the race and ethnic origin of a person.

Another biological record that remains unchanged throughout the lifetime of a person is blood group. In the present study, $\mathrm{B}^{+}$blood group was the predominant group found followed by $\mathrm{A}^{+}, \mathrm{O}^{+}$and $\mathrm{AB}^{+}$in both males and females which is in contrast to the study done by previous authors ${ }^{5,6}$ who found $\mathrm{O}^{+}$as a major blood group followed by $\mathrm{B}^{+}, \mathrm{A}^{+}$, $\mathrm{AB}^{+}, \mathrm{A}^{-}$and $\mathrm{AB}^{-}$. In this study, it was found that the lip pattern of Type I, I', and Type II in $\mathrm{B}^{+}$individuals, Type I, II and III in $\mathrm{A}^{+}$individuals, Type I, II, III in $\mathrm{AB}^{+}$individuals and Type II, III, I in $\mathrm{O}^{+}$individuals which were also same in the study done by other researchers ${ }^{6,7,8,9}$.

Regarding the classification system, most of the previous studies, $90,11,12$ considered Suzuki and Tsuchihashi classification but Dina Shokry et al ${ }^{13}$ took Renaud's classification which is considered as the most complete classification according to his study criteria. In this study, we found no significant correlation between ABO blood groups and lip pattern as all the individuals showed different lip patterns in different blood groups which proves the fact that lip patterns and blood groups of each and every person is genetically determined and develop during early fetal life which can variate according to the geographical areas ${ }^{14,15,16,17,18,19,20,21}$.

\section{CONCLUSIONS}

The result of our study pertains that no correlation exists between lip prints and $\mathrm{ABO}$ blood group but this study provides a baseline concept to the fact that large number of sample size from different geographical regions can be taken to prove the relationship between cheiloscopy and blood group keeping the fact in the mind that these remains unchanged during the lifetime of a person and might help in forensic identification processing the future.

\section{REFERENCES}

1. Prerna Gupta, Neeraj Gupta, Bannur B M, Anand B Mugadlimath, Mandar Ramchandra Sane, Rekha Hiremath. A study of correlation of Cheiloscopy and blood group. Journal of forensic medicine, science and law; 2014: 23(1), 1-6. 
2. Vahanwalla S P, Parekh B K. study on lip prints as an aid to forensic methodology. J Forensic Med and Toxicol. 2000; 17(1); $12-18$.

3. Rastogi P and Prida A. Lip prints- an aid in identification. Australian Journal of forensic sciences. 2011; 1-8, i first article.

4. Vahanwalla S P, Nayak C D, Pagare SS. Study of lip prints as aid for sex determination. Medico-Legal update.2005; 5(3): 9398.

5. Harsha L, Jayaraj Gifrina. Correlation of lip print, finger print and blood groups in a Tamil Nadu based population. J.Pharm.Sci. \& Res. 2015; 7(9): 795-799.

6. Pranita R Viveki, Kasturi B Hunshikatti. A study of dactylography and cheiloscopy patterns and their relationship with ABO blood groups. Journal of medicalscience and clinical research. 2014; 2(12): 3192-3201.

7. Anwesh Biswas, G Subhas Babu, Mahabalesh Shetty, Kumuda Rao, Balaji Narayan, Soundarya Sakthivel. Correlation of lip prints, palm prints and ABO blood goups among students based population in Mangalore. International Journal of Applied DentalSciences. 2020; 6(4): 452-458.

8. Rajni Thakur, Deepti Gautam. Reciprocity of blood group with gender and dactylographicpattern, Cheiloscopy among dental students of Chhattisgarh. International journal of advance study and research work. 2020; 3(2):31-39.

9. Deepti Gautam, Rajni Thakur. Variation of cheiloscopy and blood groups among tribal belt physiotherapy college student in Chhattisgarh. International journal of developmental research. 2019; 9(11): 32078-32080.

10. Srigiri Surath, Sushma Bommanavar, Sudha B Mattigatti, Uzma Belgaumi, Vidya Kadashetti, Wasim Kamate, NupuraVibhute. Correlation and comparison of cheiloscopy, dactyloscopy and palatoscopy with blood groups among dental students from western Maharashtra. Indian journal of forensic medicine and toxicology.2020; 14(1): 99-104

11. Manal Hassam Abdel Aziz, Fatma Mohamed Magdy Badr El Dine, Nourhan Mohamed Mohamed Saeed. Cheiloscopy and dactylography in relation to ABO blood groups: Egyptian vs Malay populations. International scholarly and scientific research \& innovation. 2019; 13(2): 123-128.

12. Sneha Khanapure, Suhas H G, Shrudha Potdar, George Sam, Sudeep C B, Arjun M R. association between cheiloscopic patterns and ABO blood groups among south Indian population. The journal of contemporary dental practice. 2017; 18(7): 596-600.

13. Dina A Shokry, Naglaa F Mahmoud, Mostafa M Afify. A study of morphological patterns of lip prints in relation to gender and blood group among Egyptian Population. Egypt J. Forensic Sci.Appli. Toxicol. 2017; 17(1):223-236.

14. Smrirti Ramdas, Sushma Bommanavar, Rajendra Baad, Nupura Vibhute, Uzma Belgaumi, Vidya Kadashetti, Wasim Kamate. Correlation and comparison of dactyloscopy and palatoscopy with blood groups among dental students from western Maharashtra. Medical journal of Dr.D Y Patil Vidyapeeth. 2019; 12: 111-5.

15. Srilekha N, Anuradha A, Vijay Srinivas G, Sabitha Devi R. Correlation among lip print pattern, finger print pattern and ABO blood group. Journal of clinical and diagnostic research. 2014; 8(3): 49-51.

16. K Srinivasulu, Padma Sri Katikaneni, Vaidarshi Abbagoni, Sowmya Bhashini Popuri, T Rahul Reddy. Study on pattern of lip prints and its relation to sex and blood groups in Telangana population. Medico-legal update. 2020; 20(4): 267-272.

17. Harpreet Sandhu, Pradhuman Verma, Sarfaraz Padda, Seetharamaiha Sunder Raj. Frequency and correlation of lip prints, fingerprints and ABO blood groups in population of Sriganganagar district, Rajasthan. Acta medica academica.2017; 46(2): 105-115. 
18. Ashwinirani S R, Girish Suragimath, Abhijeet R Sande, Prasad Kulkarni, Anand Nimbal, T Shankar, T Snigdha Gowd,Prajwal $K$ Shetty. Comparison of lip prints in two Indian subpopulations and its correlation in ABO blood groups. Journal of clinical and diagnostic research. 2014; 8(10): ZC40-ZC43.

19. Sonaj Vardhaman, Anirudha Bartake, Sangeeta Palaskar, Vineet Vinay, Bindya Narang. Comparative analysis of lip prints, fingerprints and blood groups: A cross sectional study. Indian journal of applied research. 2017; 7(1):741-743.

20. Saba Rashid, Anu Singla. A statistical study of lip print, fingerprint and ABO blood grouping and their significance in personal identification. Research journal of forensic sciences. 2019; 7(2): 1-7.

21. Rosamma George, Kavya Shree. Lip prints and blood groups, among two South Indian population- An in vivo study. International journal of dental research \& development. 2017; 7(4): 1-7 
